\title{
Preface
}

\section{Complications in Plastic Surgery}

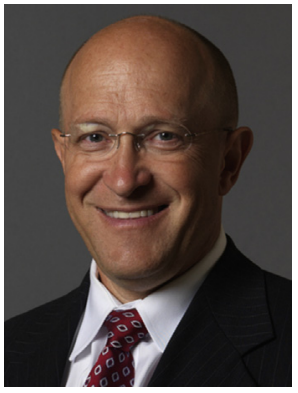

Dennis C. Hammond, MD Editor

Breast reduction is one of the most commonly performed procedures in plastic surgery, and many different techniques have been described to accomplish this task. However, concentrated information on the management of complications associated with this workhorse operation is lacking. This was the impetus for this issue of Clinics in Plastic Surgery. The content is organized into four subcategories, including (1) general considerations in breast reduction and management of issues related to breast cancer; (2) specific discussion of complication management for each of the common techniques in breast reduction; (3) management of specific complications common to all techniques and management of specific difficult types of patients; and (4) management of medicolegal issues related to breast reduction. Each of the authors is a recognized expert in plastic surgery of the breast, and I would specifically like to extend my sincere gratitude for their efforts in making this a highlight issue of this very respected series, Clinics in Plastic Surgery. It is my hope that you, the reader, will find this information useful in the management of your own patients.

Dennis C. Hammond, MD Partners in Plastic Surgery 4070 Lake Drive, Suite 202 Grand Rapids, MI 49546, USA

E-mail address: drhammond@pipsmd.com 